\title{
Outcome of Prophylactic Noninvasive Ventilation Following Planned Extubation in High-risk Patients: A Two-year Prospective Observational Study from a General Intensive Care Unit
}

\author{
Supradip Ghosh ${ }^{1}$, Aayush Chawla ${ }^{2}$, Ranupriya Jhalani ${ }^{3}$, Ripenmeet Salhotra ${ }^{4}$, Garima Arora ${ }^{5}$, Satyanarayan Nagar ${ }^{6}$, \\ Abhay S Bhadauria ${ }^{7}$, Kirtee Mishra ${ }^{8}$, Amandeep Singh ${ }^{9}$, Aditya Lyall ${ }^{10}$
}

\begin{abstract}
Introduction: Prophylactic use of noninvasive ventilation (NIV) is recommended following extubation in patients at high risk of extubation failure. In a prospective cohort study, we examined the impact of prophylactic NIV in this subset of patients, potentially exploring the risk factors for extubation failure in them and the impact of extubation failure on organ function. We also explored the effect of fluid balance on extubation failure or success in this high-risk patient subgroup.

Materials and methods: Consecutive adult patients ( $\geq 18$ years) admitted in the mixed intensive care unit (ICU) of a tertiary care center, between January 1, 2018, and December 31, 2019, who passed a spontaneous breathing trial (SBT) following at least 12 hours of invasive mechanical ventilation and put on prophylactic NIV for being at a high risk of extubation failure, were prospectively followed throughout their hospital stay. Extubation failure was defined as developing respiratory failure within 72 hours postextubation requiring reintubation or still requiring NIV support at 72 hours postextubation.

Results: A total of 85 patients were included in the study. $11.8 \%$ of patients had extubation failure at 72 hours with an overall reintubation rate of $10.5 \%$. Higher age $(p<0.05)$, longer duration of invasive ventilation $(p<0.05)$, and higher sequential organ failure assessment (SOFA) score at extubation $(p<0.05)$ were identified as risk factors for extubation failure in univariate analysis. However, in the multivariate analysis, only a higher SOFA score remained statistically significant in forward logistic regression analysis $(p<0.05)$. We found a clear trend toward worsening organ function score in the extubation failure group in the first 72 hours postextubation, suggesting extubation failure as a risk factor for organ dysfunction. Cumulative fluid balance was higher both at extubation and in subsequent 3 days postextubation in the failure group, but the differences were not statistically significant. Conclusion: Higher age, longer duration of invasive ventilation, and higher baseline SOFA score at extubation remain risk factors for extubation failure even in this high-risk subset of patients on prophylactic NIV. Extubation failure is associated with the worsening of organ function. A trend toward higher cumulative fluid balance both at extubation and postextubation, suggests aggressive de-resuscitation as a potentially helpful strategy in preventing extubation failure.

Keywords: Fluid balance, General intensive care unit, High-risk of extubation failure, Organ dysfunction, Prophylactic noninvasive ventilation. Indian Journal of Critical Care Medicine (2020): 10.5005/jp-journals-10071-23673
\end{abstract}

\section{INTRODUCTION}

The decision to extubate a patient on invasive mechanical ventilation (MV) is a real challenge faced daily in the intensive care unit (ICU). Timely liberation from invasive ventilation is associated with better outcome and lower complication rates. However, failure of extubation and a need for reintubation is clearly associated with high risk of mortality and other adverse consequences including higher risk of pneumonia and longer ICU or hospital length of stay. ${ }^{1-4}$ Previous studies have identified subset of patients at a higher risk of extubation failure including older age, ${ }^{2,5}$ higher disease severity, ${ }^{2,5}$ longer duration of invasive ventilation, ${ }^{1,4}$ patients with underlying chronic obstructive airway disease with hypercapnia $\left(\mathrm{PaCO}_{2}>45\right.$ $\mathrm{mm} \mathrm{Hg}$ ) at extubation, ${ }^{6}$ congestive heart failure ${ }^{2}$ poor neurological status, ${ }^{1,7}$ underlying chronic kidney disease, ${ }_{1}^{1}$ poor cough, ${ }^{6,7}$ higher cumulative fluid balance at extubation, ${ }^{1,8}$ and previous failed spontaneous breathing trial (SBT). ${ }^{9}$

Noninvasive ventilation (NIV) had been proposed as a potential strategy in reducing reintubation. Earlier studies in unselected patient population NIV failed to avoid the need for reintubation ${ }^{10-12}$ and indeed in some of these studies, the strategy
1-5,8-10 Department of Critical Care Medicine, Fortis-Escorts Hospital, Faridabad, Haryana, India

${ }^{6}$ Department of Anesthesia and Critical Care Medicine, MP Birla Hospital, Chittorgarh, Rajasthan, India

${ }^{7}$ Department of Critical Care Medicine, Medanta Hospital, Lucknow, Uttar Pradesh, India

Corresponding Author: Supradip Ghosh, Department of Critical Care Medicine, Fortis-Escorts Hospital, Faridabad, Haryana, India, Phone: +919818590021, e-mail: intensivist1972@gmail.com

How to cite this article: Ghosh S, Chawla A, Jhalani R, Salhotra R, Arora G, Nagar S, et al. Outcome of Prophylactic Noninvasive Ventilation Following Planned Extubation in High-risk Patients: A Two-year Prospective Observational Study from a General Intensive Care Unit. Indian J Crit Care Med 2020;24(12):1 185-1192.

Source of support: Nil

Conflict of interest: None

was associated with higher ICU mortality. ${ }^{10}$ No difference in mortality and reintubation rate was observed when NIV was used in patients with postextubation respiratory distress ${ }^{13}$. In contrast, 
when applied immediately after planned extubation in patients at high risk of extubation failure, NIV was found to be effective in reducing postextubation respiratory failure and reintubation. ${ }^{14-16}$ In a related study, Girault and colleagues randomized 208 chronic hypercapnic respiratory failure patients who failed their first SBT, into three groups: conventional invasive weaning, extubation and standard oxygen therapy and extubation, and prophylactic NIV. ${ }^{17}$ Both early extubation strategies followed by either standard oxygen or prophylactic NIV groups received invasive ventilation for at least 30 minutes of post-SBT failure. The reintubation rate in the first 7 days was not different between the three groups but the use of NIV could significantly decrease the duration of intubation. ${ }^{17}$ Based on the results of these later trials, recent guidelines have now suggested the use of prophylactic NIV in this category of patients at high risk of extubation failure. ${ }^{18,19}$ Noninvasive ventilation is now increasingly being used in ICUs postextubation in high-risk patients. In an earlier study by our group, looking for risk factors of postextubation respiratory failure, prophylactic NIV was used as high as $46.2 \%$ of patients after planned extubation. ${ }^{1}$

Most studies so far have addressed the issue of prophylactic NIV use in the setting of randomized control trials (RCTs). There was a need to conduct a longitudinal study in a real-world scenario looking for the overall impact of prophylactic NIV in these patients at high risk of extubation failure. We, therefore, planned to conduct a two year prospective study of extubation outcomes in patients who were considered to be at a high risk of extubation failure and were put on prophylactic NIV support immediately after extubation in our ICU. Our objective was to evaluate the risk factors for extubation failure in this subgroup of patients. We hypothesized a significant worsening in organ dysfunction in patients with failed extubation and looked for changes in daily organ dysfunction scores after successful and failed extubation. We also hypothesized higher fluid balance in the extubation failure group in days following extubation and looked for changes in the daily fluid balance after successful and failed extubation.

\section{Materials and Methods}

We undertook a prospective observational cohort study, in the 18-bed mixed ICU of Fortis-Escorts Hospital, Faridabad from January 1,2018 , to December 31, 2019. In the unit, a critical care team led by a consultant intensivist is available at $24 \times 7$ and nurse to patient ratio is maintained between 1:1 and 1:2. The study was approved by the Institutional Ethics Committee (EC/2018/16, signed 12/02/2018), and written informed consent was obtained from patients' relatives before enrolling in the study.

\section{Study Population}

Patients receiving invasive MV for at least 12 hours were screened daily weanability criteria as described previously. ${ }^{20}$ They were followed up prospectively, while undergoing daily SBTs, until successful completion of an SBT. All patients over 18 years of age, who underwent planned extubation after a successful SBT and considered for prophylactic NIV postextubation for estimated highrisk of extubation failure were included in the study. Patients were considered at high-risk for extubation failure if they fulfilled any of the following criteria as described in earlier studies: ${ }^{.4,15}$ (1) Known or suspected chronic obstructive airway disease (COAD) with $\mathrm{PaCO}_{2}>45$ $\mathrm{mm} \mathrm{Hg}$ at extubation. (2) Patients with age $>65$ years. (3) History of chronic heart failure (New York Heart Association class II-IV) or left ventricular ejection fraction $<40 \%$. (4) Patients with prior failed SBT.
(5) Patients with two or more organ system failure other than chronic respiratory or heart failure. ${ }^{14,15}$ Data were collected only for the first episode of extubation. Patients were excluded from the study if they meet any of the following conditions: craniofacial trauma or surgery, ongoing upper gastrointestinal bleeding, excessive respiratory secretions or inability to handle secretion, recurrent vomiting, recent gastric or esophageal surgery, tracheostomized, perceived lack of cooperation, already on home NIV, the decision to limit therapeutic intervention, and refusal of consent.

\section{Procedure}

All ventilated patients were screened daily for weanability criteria and patients fulfilling these criteria were put on a trial of SBT. The technique of SBT [T-piece or low-level pressure support of 6-8 cm of $\mathrm{H}_{2} \mathrm{O}$ with positive end-expiratory pressure (PEEP) of $3-5 \mathrm{~cm} \mathrm{H}_{2} \mathrm{O}$ ] and duration of the trial (30-12 minutes) were at the discretion of the attending intensivist. Successful SBT was defined as per international guidelines. ${ }^{21}$ All patients who passed the SBT were directly extubated.

All consenting patients, considered at high-risk for extubation failure, were put on prophylactic NIV support starting immediately after extubation using an ICU ventilator with a specific NIV algorithm (Maquet Servo-S or Servo-I, Maquet Critical Care AB, Solna, Sweden). Noninvasive ventilation was delivered using an appropriate size full-face mask (Fisher \& Paykel Healthcare SA de CV, Tijuana, Baja California, Mexico or ResMed Ltd., New South Wales, Australia). After explaining the process facemask was applied, the ventilator support system was initiated at a PEEP of $4-6 \mathrm{~cm}$ of $\mathrm{H}_{2} \mathrm{O}$ and pressure support of $4-6 \mathrm{~cm}$ of $\mathrm{H}_{2} \mathrm{O}$ and was gradually titrated to achieve a tidal volume of $6-9 \mathrm{~mL} / \mathrm{kg}$ of predicted body weight and a respiratory rate of around 20-25 breaths per minute without significant patient-ventilator dyssynchrony. The fraction of inspired oxygen and PEEP was titrated to maintain the oxygen saturation by pulse oximetry above $90 \%$. Ventilator settings were subsequently adjusted as needed for the patient's comfort, for maintaining $\mathrm{SpO}_{2}$, for minimizing patient-ventilator dyssynchrony, and to target a $\mathrm{pH}$ above 7.35. The goal was to apply NIV support continually for 6-12 hours postextubation except for 15-20-minute periods to allow the patient to drink fluids or receive nursing care. After that period unassisted breathing was allowed for a gradually increasing period provided the patient is comfortable and was able to maintain adequate oxygenation and $\mathrm{pH}$ remained above 7.35. For mild agitation and intolerance to mask, sedation with dexmedetomidine (up to $0.8 \mu \mathrm{g} / \mathrm{kg} /$ hour, targeting Richmond agitation sedation scale between 0 and -2) was allowed, provided other measures to reassure patients failed to control it. Postextubation respiratory failure was defined as per literature and broadly followed international guideline: cardiac arrest, respiratory arrest, psychomotor agitation requiring sedation other than lowdose dexmedetomidine, deteriorating consciousness, heart rate $<50 /$ minute with loss of alertness, and hemodynamic instability requiring vasopressor support and deteriorating gas exchange values. $^{1,21}$ The final decision regarding the discontinuation of NIV and the need for reintubation was left to the discretion of the attending consultant intensivist.

\section{Collection of Data}

Demographic data including age, sex, time from hospital admission to intubation, time from ICU admission to intubation, underlying chronic disorder (if any), acute physiology and chronic health evaluation II (APACHE II) as an indicator of disease severity and 
indication for intubation were collected for all patients at baseline. Chronic cardiovascular disease was defined as patients with moderate-to-severe left ventricular dysfunction (left ventricular ejection fraction $<40 \%$ ) or in New York Heart Association (NYHA) class III or IV. Chronic respiratory disease was categorized as patients with significant restriction of activities or requirement of home oxygen therapy or NIV support at home. Patients with baseline restriction of activities of daily living or having pharyngeal dysfunction because of a previously diagnosed neurological disorder (e.g., cerebrovascular accident or parkinsonism or dementia) were identified as patients with chronic neurological disease. End-stage renal disease (ESRD) was identified using standard criteria (may or may not be on chronic dialysis support). ${ }^{22}$

Following data were collected at extubation: duration of MV before extubation, respiratory rate, heart rate, mean arterial pressure, lactate level, net cumulative fluid balance at extubation (total intake including oral and intravenous fluid, medications, and blood products since hospital admission minus total output including urine, drains output and ultrafiltration if any), and arterial blood gas values $(\mathrm{pH}$, the partial pressure of carbon dioxide$\mathrm{PaCO}_{2}$, the ratio of the partial pressure of oxygen to fractional inspiratory oxygen- $\mathrm{PaO}_{2} / \mathrm{FIO}_{2}$ ratio). For assessing changes in the severity of organ dysfunction and its relationship with failure of extubation, sequential organ failure assessment (SOFA) scoring was done a day before extubation, on the day of extubation, and daily thereafter for the next 72 hours after extubation. Fluid balance 24 hours pre-extubation, 24, 48, and 72 hours postextubation was recorded for each patient. For all patients, the total duration of prophylactic NIV, outcome of NIV (successful extubation, reintubation or still on NIV at 72 hours), complications of NIV (including mask intolerance, conjunctival irritation, pressure effect or agitation), hospital outcome (dead or alive), ICU, and hospital length of stay were recorded. Extubation success was defined as patients free from NIV support at 72 hours postextubation without a need for reintubation. Other patients who were reintubated within 72 hours post index extubation or who remained on NIV support at 72 hours were diagnosed with extubation failure. For patients requiring reintubation, the time elapsed from index extubation to reintubation and specific indications for reintubation were recorded.

All patients were followed up till hospital discharge. Following outcome data were recorded at discharge from hospital: outcome of hospitalization (survival or death), ICU length of stay, and hospital length of stay. The worst possible outcome (death) was recorded as the hospital outcome for patients in whom family wished to discontinue further treatment.

\section{Statistical Analysis Plan}

Results are summarized as mean \pm standard deviation for normally distributed quantitative variables, median with interquartile range Q1-Q3 for non-normally distributed quantitative variables, and frequency (and percentage) for qualitative variables. For significance testing, the following statistical tests were used as appropriate: parametric unpaired Student's $t$-test for normally distributed variables, Mann-Whitney $U$ test for non-normally distributed variables, and the Pearson's Chi-squared test/Fisher's exact test to compare proportions. Two-tailed $p$ values of $<0.05$ was taken as a level of statistical significance. To identify independent factors related to extubation failure and to negate the effects of confounding variables, we performed a conditional stepwise multivariable logistic regression analysis (both forward and backward) including independent variables not distributed evenly between the two groups of study in the univariate analysis ( $p<$ 0.05 ) and pre-specified variables including baseline cumulative fluid balance and indication for applying NIV (COAD with hypercapnia at extubation or non-COAD). Statistical analysis is performed using the statistical software package SPSS version 22.0 (SPSS, Chicago, IL, USA).

\section{Results}

\section{At ICU Admission}

During the study period, 85 patients were put on prophylactic NIV following their index extubation-9 of them required reintubation within 72 hours and 1 was still on NIV support at 72 hours postextubation. Thus, the rate of extubation failure in this high-risk population was $11.8 \%$ as per the study definition. A lone patient who was on NIV at 72 hours could be weaned off from NIV on day- 5 postextubation. Table 1 shows the baseline characteristics of the patients according to their extubation success and failure status. Compared with successfully extubated patients, patients with failed extubation were older at baseline. However, no significant differences were found regarding hospital or ICU days before extubation, sex distribution, underlying chronic cardiac, respiratory, kidney, or neurological diseases, baseline severity of illness, or indications for intubation. The mean time to reintubation was 27 ( \pm 21.44 ) hours. Reasons for reintubation were worsening of oxygenation ( $N=4,44.5 \%)$, worsening $\mathrm{pH}$ and rise in $\mathrm{PaCO}_{2}(N=1$, $11.1 \%)$, worsening mental status or extreme agitation $(N=2,22.2 \%)$, and refractory hypotension $(N=2,22.2 \%)$.

\section{At the Time of Extubation}

Median duration of invasive ventilation ( 2.87 vs 1.75 days, $p<0.05$ ) and SOFA score ( $4 \pm 2.4$ vs $2.7 \pm 1.6, p<0.05)$ were significantly higher at index extubation in the failure group. In contrast, there was no difference in heart rate, respiratory rate, mean arterial pressure, blood gas variables $\left(\mathrm{pH}, \mathrm{PaCO}_{2}\right.$, or $\mathrm{PaO}_{2}: \mathrm{FIO}_{2}$ ratio), lactate, cumulative fluid balance, or indications for prophylactic NIV at the time of extubation. Table 2 shows different parameters in both extubation success and failure groups at the time of extubation. The commonest indication for applying prophylactic NIV was underlying COAD with $\mathrm{PaCO}_{2}>45 \mathrm{~mm} \mathrm{Hg}$ at extubation (56.5\%). The rate of extubation failure in patients with "COAD with $\mathrm{PaCO}_{2}$ $>45 \mathrm{~mm} \mathrm{Hg}$ at extubation" was $10.4 \%$, compared to $13.5 \%$ in other patients and the difference was not statistically significant ( $p=$ 0.74). In the logistic regression analysis, a statistically significant association with extubation failure was seen only with total SOFA score at extubation in forward regression $(p<0.05)$; however, the level of significance was borderline in backward regression ( $p=$ 0.054).

\section{Evolution of Severity Score before and after Extubation}

As shown in Figure 1, the evolution of SOFA score differed in first 72 hours after extubation in success and failure groups, with total SOFA score gradually decreasing in successful extubation group indicating improvement in clinical status. In contrast, total SOFA score substantially worsened in the extubation failure group. However, the difference in total SOFA score between two groups reached statistical significance only on the day of extubation 
Table 1: Baseline characteristics at initial intubation

\begin{tabular}{|c|c|c|c|c|}
\hline Parameter & Total $(N=85)$ & Success $(N=75)$ & Failure $(N=10)$ & $p$ value \\
\hline Age, years (mean $\pm S D$ ) & $65 \pm 12$ & $64 \pm 12$ & $72 \pm 8$ & $<0.05$ \\
\hline Male sex, no. (\%) & $58(68.2 \%)$ & $51(68 \%)$ & $7(70 \%)$ & 1 \\
\hline Hospital days before intubation (median [range]) & $2(0-8)$ & $1(0-7)$ & $5.5(3-8)$ & 0.94 \\
\hline ICU days before intubation (median [IQR]) & $1.5(0.25-8)$ & $1(0.25-7)$ & 8 & 0.87 \\
\hline Severe underlying cardiac disease, no. (\%) & $12(14 \%)$ & $9(12 \%)$ & $3(30 \%)$ & 0.14 \\
\hline Severe underlying respiratory disease, no. (\%) & $70(82 \%)$ & $62(82 \%)$ & $8(80 \%)$ & 1 \\
\hline Severe underlying kidney disease, no. (\%) & $6(7 \%)$ & $4(5 \%)$ & $2(20 \%)$ & 0.14 \\
\hline Severe underlying neurological disease, no. (\%) & $2(2 \%)$ & $1(1 \%)$ & $1(10 \%)$ & 0.22 \\
\hline APACHE II score on the day of intubation (mean \pm SD) & $15 \pm 6$ & $15 \pm 6$ & $16 \pm 5$ & 0.54 \\
\hline Indications for intubation, no. (\%) & & & & 0.25 \\
\hline Poor GCS, no. (\%) & $2(2 \%)$ & $1(1.3 \%)$ & $1(10 \%)$ & 0.22 \\
\hline Hypoxemic respiratory failure, no. (\%) & $14(16.5 \%)$ & $13(17.3 \%)$ & $1(10 \%)$ & 1 \\
\hline Hypercapnic respiratory failure, no. (\%) & $62(72.9 \%)$ & $55(73.3 \%)$ & $7(70 \%)$ & 0.82 \\
\hline Worsening shock, no. (\%) & $2(2.4 \%)$ & $2(2.7 \%)$ & 0 & 1 \\
\hline Postoperative, no. (\%) & $3(3.5 \%)$ & $3(4 \%)$ & 0 & 1 \\
\hline Poor respiratory effort, no. (\%) & $2(2.4 \%)$ & $1(1.3 \%)$ & $1(10 \%)$ & 0.22 \\
\hline
\end{tabular}

GCS, Glasgow coma scale; ICU, intensive care unit; IQR, interquartile range; SD, standard deviation

Table 2: Parameters at extubation

\begin{tabular}{|c|c|c|c|c|}
\hline Parameter & Total $(N=85)$ & Success $(N=75)$ & Failure $(N=10)$ & pvalue \\
\hline Invasive ventilation days before extubation (range) & $1.75(0.5-11.75)$ & $1.75(0.5-11.75)$ & $2.87(1-7.75)$ & $<0.05$ \\
\hline SOFA score on day of extubation (mean \pm SD) & $2.8 \pm 1.6$ & $2.7 \pm 1.6$ & $4 \pm 2.4$ & $<0.05$ \\
\hline Heart rate/minute at extubation (mean $\pm \mathrm{SD}$ ) & $97 \pm 14$ & $97 \pm 14$ & $93 \pm 16$ & 0.42 \\
\hline Respiratory rate/minute at extubation (mean \pm SD) & $23 \pm 3$ & $23 \pm 3$ & $23 \pm 4$ & 0.93 \\
\hline Mean arterial pressure at extubation (mean \pm SD) & $84 \pm 14$ & $83 \pm 14$ & $87 \pm 16$ & 0.55 \\
\hline $\mathrm{pH}$ at extubation (mean $\pm \mathrm{SD}$ ) & $7.4 \pm 0.05$ & $7.4 \pm 0.05$ & $7.4 \pm 0.05$ & 0.97 \\
\hline $\mathrm{PaCO}_{2}$ in $\mathrm{mm} \mathrm{Hg}$ at extubation (mean $\pm \mathrm{SD}$ ) & $48.32 \pm 12$ & $48.73 \pm 12.19$ & $45.25 \pm 10.52$ & 0.35 \\
\hline $\mathrm{PaO}_{2} / \mathrm{FIO}_{2}$ ratio at extubation (mean $\pm \mathrm{SD}$ ) & $226.63 \pm 50.80$ & $225.56 \pm 46.20$ & $234.64 \pm 80.36$ & 0.73 \\
\hline Lactate in $\mathrm{mmol} / \mathrm{L}$ at extubation (mean $\pm \mathrm{SD}$ ) & $0.9 \pm 0.4$ & $0.9 \pm 0.4$ & $0.7 \pm 0.3$ & 0.17 \\
\hline Cumulative fluid balance in $\mathrm{mL}$ (mean $\pm \mathrm{SD}$ ) & $1785 \pm 2080$ & $1648 \pm 1870$ & $2810 \pm 3208$ & 0.28 \\
\hline Indications for prophylactic NIV, no. (\%) & & & & 0.58 \\
\hline COAD with $\mathrm{PaCO}_{2}>45 \mathrm{~mm} \mathrm{Hg}$ at extubation, no. (\%) & $48(56.5 \%)$ & $43(57.3 \%)$ & $5(50 \%)$ & 0.74 \\
\hline $\begin{array}{l}\text { Age }>65 \text { years with or without chronic cardiac or respiratory illness, no. } \\
\text { (\%) }\end{array}$ & $15(17.6 \%)$ & $13(17.3 \%)$ & $2(20 \%)$ & 1 \\
\hline History of CHF or LVEF $<40 \%$, no. (\%) & $9(10.6 \%)$ & $8(10.7 \%)$ & $1(10 \%)$ & 1 \\
\hline Prior failed SBT, no. (\%) & $6(7.1 \%)$ & $6(8 \%)$ & $0(0 \%)$ & 1 \\
\hline $\begin{array}{l}\text { Two or more organ system failure other than chronic respiratory or heart } \\
\text { failure, no. }(\%)\end{array}$ & $7(8.2 \%)$ & $5(6.7 \%)$ & $2(20 \%)$ & 0.19 \\
\hline
\end{tabular}

$\mathrm{CHF}$, congestive heart failure; COAD, chronic obstructive airway disease; $\mathrm{LVEF}$, left ventricular ejection fraction; $\mathrm{NIV}_{\text {, noninvasive ventilation; } \mathrm{PaCO}}$, partial pressure of carbon dioxide; $\mathrm{PaO}_{2} / \mathrm{FIO}_{2}$, a ratio of partial pressure of oxygen and fractional inspiratory oxygen; SD, standard deviation; SOFA, sequential organ failure assessment.

(day 0 ) and a day after extubation (day +1 ) as can be seen in Table 3. As can be seen in Figure 2, a similar trend was observed even for individual organ SOFA score.

\section{Fluid Balance}

We did not find a difference in cumulative fluid balance between the groups at baseline $(p=0.28)$. Compared to the successful extubation group, fluid balances were more positive in the failure group in subsequent days, as can be seen in Figure 3. However, the differences were not statistically significant (Table 4).

\section{Outcome}

Mean duration of NIV support was 29.49 ( \pm 14.82$)$ hours and was not significantly different between the success and failure groups (Table 5). A total of 17 adverse events were recorded during the study period: 3 patients had intolerance to mask, 3 had conjunctival irritation, 1 had nasal bridge induration, 1 had abdominal distention, and 8 patients had significant agitation requiring dexmedetomidine infusion. Rate of adverse events were significantly higher in failure group compared to successful extubation group ( 80 vs $12 \% ; p<0.001$ ). Overall, ICU mortality in the 
study population was $9.49 \%$ and was significantly higher in failure group ( $50 \%$ vs $4 \%, p<0.001)$. There was no statistically significant difference in ICU or hospital length of stay between successful and failed extubation groups.

\section{Discussion}

To our knowledge, this is the first study addressing outcomes of prophylactic NIV at extubation after a planned extubation, in patients at a high risk of extubation failure, outside the scope of $\mathrm{RCT}$. The overall rate of extubation success at 72 hours was $88.2 \%$. Those who failed their initial extubation attempt had higher age, longer duration of invasive ventilation, and higher SOFA score at extubation. When we compared patients with failed and successful extubation, a trend toward worsening organ function was observed in failure group during first 72 hours postextubation. We also observed a trend toward higher cumulative fluid balance in first 72 hours postextubation in the failure group.

\section{Comparisons with Earlier Studies}

In the first-ever RCT, Nava and colleagues tested the strategy of prophylactic NIV in patients considered to be at a high risk of extubation failure following at least 48 hours of invasive ventilation and successful SBT. ${ }^{15}$ At 48 hours, rate of reintubation was significantly lower in prophylactic NIV group compared to control group ( 8 vs $24 \%$ ). Use of NIV was associated with significantly lower

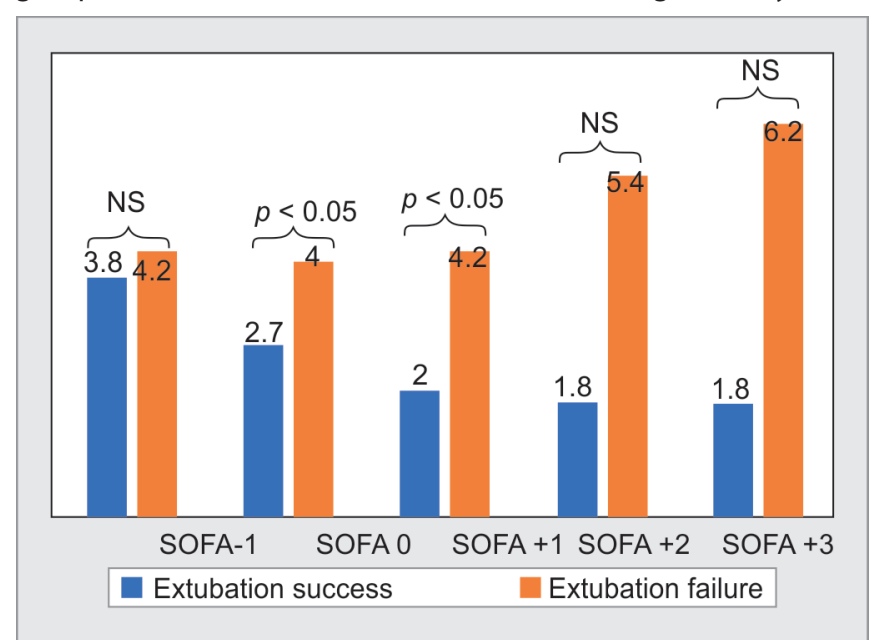

Fig. 1: Changes in mean SOFA score in extubation success and failure groups from day before extubation till day 3 after extubation. NS, not statistically significant; SOFA -1, SOFA score, the day before extubation; SOFA +1 , SOFA score on day 1 postextubation; SOFA +2 , SOFA score on day 2 postextubation; SOFA +3 , SOFA score on day 3 postextubation; SOFA 0 , SOFA score on the day of extubation; SOFA, sequential organ failure assessment
ICU mortality and ICU length of stay. Unlike our study where we applied NIV immediately postextubation, Nava and colleagues applied NIV only after 1 hour of extubation, potentially exacerbating low frequency diaphragmatic fatigue and atelectasis. ${ }^{23}$ In a later RCT, Ferrer and colleagues applied NIV immediately postextubation in the intervention group. ${ }^{14}$ They also added age $>65$ years and APACHE II score $>12$ at extubation as additional criteria for high risk of extubation. Post-extubation respiratory failure was significantly lower in NIV group (16 vs 33\%). But there was no difference in rate of reintubation between groups; likely because NIV was applied as rescue therapy in some of the patients in control group following postextubation respiratory failure. In the multivariable analysis, ICU mortality and 90-day mortality were significantly lower in NIV group; limited only to patients with hypercapnia at extubation with the underlying chronic respiratory disorder. ${ }^{14}$ Based on this findings, Ferrer and colleagues conducted another RCT, testing prophylactic NIV in patients with underlying chronic respiratory illness and hypercapnia at extubation. ${ }^{16}$ Application of prophylactic NIV was associated with significantly lower respiratory failure at 48 hours postextubation and significantly lower 90 -day mortality, compared to control group receiving conventional oxygen therapy. ${ }^{16}$ The rate and mean time to reintubation in our study were $10.5 \%$ (9 of 85 patients) and 23 hours, respectively. Both were comparable with the intervention arms of earlier studies - $8 \%$ in study by Nava et al. (time to reintubation not specified in their manuscript), ${ }^{15} 9 \%$ and 41 hours in the first study by Ferrer et al. ${ }^{14}$ and $8 \%$ and 29 hours in the second study by Ferrer and colleagues. ${ }^{16}$

In a prospective observational study, Thille and colleagues identified age $>65$ years and having the underlying cardiac or respiratory disease at a high risk of extubation failure. ${ }^{4}$ In the same study, they also prospectively followed organ function with SOFA scoring for 72 hours postextubation. Organ function showed significant improvement in extubation success group, with a worsening of the same in the failure group. ${ }^{4}$ We observed a similar trend of worsening organ dysfunction in our cohort too, suggesting a link between extubation failure and worsening of organ function. In a follow-up study, Thille and colleagues applied prophylactic NIV to 153 high-risk patients (as identified by their earlier study).$^{24}$ Compared to 83 patients at high risk of extubation failure in their earlier cohort, patients in the later cohort receiving prophylactic NIV had a significantly lower rate of reintubation (28 vs 15\%). ${ }^{24}$ In the multivariate analysis of this before and after study, use of prophylactic NIV was independently associated with extubation success; but only in patients at high risk of extubation failure. ${ }^{24}$

Higher cumulative fluid balance at extubation was identified as an independent risk factor for extubation failure in patients after planned extubation in two earlier studies-one by our group ${ }^{1}$ and the other by Upadya and colleagues. ${ }^{8}$ In this study, we observed

Table 3: Comparison of SOFA score between extubation success and failure groups from day before extubation (day -1$)$ till day 3 (day +3 ) after extubation

\begin{tabular}{|c|c|c|c|c|c|}
\hline & SOFA score $($ day -1$)$ & SOFA score (day 0) & SOFA score $($ day +1$)$ & SOFA score $($ day +2$)$ & SOFA score $($ day +3$)$ \\
\hline $\begin{array}{l}\text { Extubation success, } \\
\text { mean } \pm S D(N=75)\end{array}$ & $3.8 \pm 2.2$ & $2.7 \pm 1.6$ & $2 \pm 1.5$ & $1.8 \pm 1.7$ & 1.8 \\
\hline $\begin{array}{l}\text { Extubation failure, } \\
\text { mean } \pm S D(N=10)\end{array}$ & $4.2 \pm 1.6$ & $4 \pm 1.6$ & $4.2 \pm 2.4$ & $5.4 \pm 2.7$ & $6.2 \pm 3.9$ \\
\hline$p$ value & 0.339 & $<0.05$ & $<0.01$ & 0 & 0 \\
\hline
\end{tabular}

Day -1 , day before extubation; Day +1, day 1 after extubation; Day +2 , day 2 after extubation; Day +3, day 3 after extubation; Day 0, day of extubation; $\mathrm{SD}$, standard deviation; SOFA, sequential organ failure assessment 

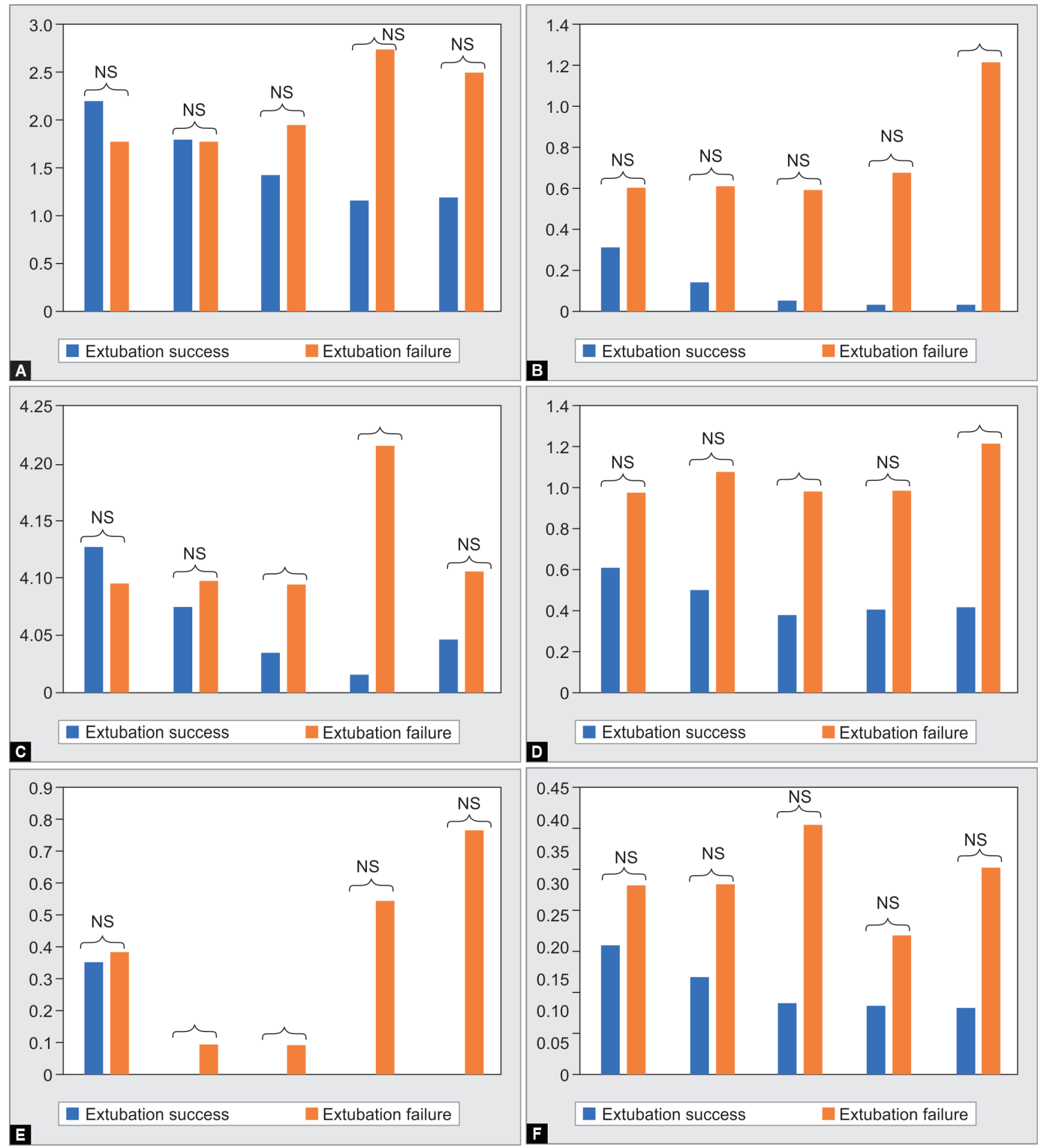

Figs $2 \mathrm{~A}$ to $\mathrm{F}$ : Mean individual organ SOFA score in extubation success and failure groups from day before extubation (day -1$)$ till day 3 (day +3 ) after extubation. Day -1 , day before extubation; Day +1 , day 1 postextubation; Day +2 , day 2 postextubation; Day +3 , day 3 postextubation; Day 0 , the day of extubation; NS, not statistically significant; SOFA, sequential organ failure assessment

a trend toward higher cumulative fluid balance at extubation and in subsequent 3 days postextubation in failure group but the differences were not statistically significant in any point. However, mean cumulative fluid balance in the failure group was much lower in the current study compared to our previous study (4336.5 vs $2810 \mathrm{~mL})^{1}$

\section{Limitations}

Our study had several limitations. First, being a single-center study, the result of our study may not be extrapolated to other centers. However, the reintubation rate and time to reintubation in our study were similar to the NIV arms of earlier studies. Second, in our study, the final decision to reintubation was not protocolized and was at 


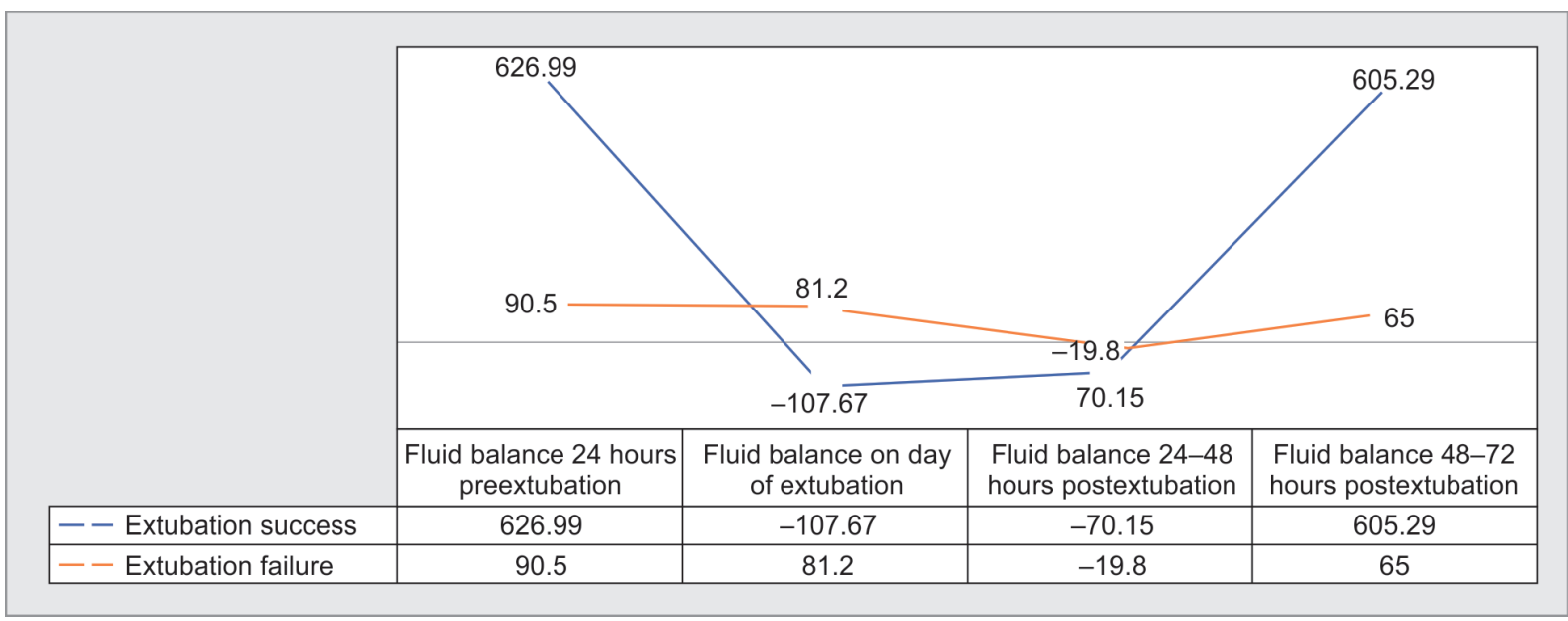

Fig. 3: Mean fluid balance (in $\mathrm{mL}$ ) in extubation success and failure groups from day before extubation till day 3 after extubation

Table 4: Comparison of fluid balance between extubation success and failure groups from day before extubation (day -1 ) till day 3 (day +3 ) after extubation

\begin{tabular}{lllll}
\hline & $\begin{array}{l}\text { Fluid balance 24 hours } \\
\text { pre-extubation }\end{array}$ & $\begin{array}{l}\text { Fluid balance On the } \\
\text { day of extubation }\end{array}$ & $\begin{array}{l}\text { Fluid balance 24 to 48 } \\
\text { hours postextubation }\end{array}$ & $\begin{array}{l}\text { Fluid balance 48 to } 72 \\
\text { hours postextubation }\end{array}$ \\
\hline Extubation success (in $\mathrm{mL}$ ), mean \pm SD & $626.99 \pm 1021.04$ & $-107.67 \pm 712.06$ & $-70.15 \pm 847.62$ & $65 \pm 584.49$ \\
Extubation failure (in $\mathrm{mL}$ ), mean \pm SD & $90.5 \pm 1505.13$ & $81.2 \pm 1208.10$ & $-19.8 \pm 916.89$ & $605.29 \pm 901.97$ \\
$p$ value & 0.585 & 0.619 & 0.753 & 0.18 \\
\hline
\end{tabular}

Day -1, day before extubation; Day 0, day of extubation; Day +3 , day 3 after extubation; SD, standard deviation

Table 5: Outcome of prophylactic NIV

\begin{tabular}{lllll}
\hline Parameter & Total $(N=85)$ & Success $(N=75)$ & Failure $(N=10)$ & $p$ value \\
\hline Duration of NIV support in hours (mean \pm SD) & $29.49 \pm 14.82$ & $29.6 \pm 14.70$ & $28.70 \pm 16.54$ & 0.97 \\
Adverse effects, no. $(\%)$ & $17(20 \%)$ & $9(12 \%)$ & $8(80 \%)$ & $<0.001$ \\
Death in ICU, no. $(\%)$ & $8(9.4 \%)$ & $3(4 \%)$ & $5(50 \%)$ & $<0.001$ \\
Intensive care unit length of stay (in days) & $9.49 \pm 1.28$ & $6.89 \pm 7.68$ & $13.3 \pm 8.65$ & 0.20 \\
Hospital length of stay (in days) & $11.37 \pm 8.24$ & $10.69 \pm 8$ & $16.4 \pm 8.68$ & 0.20 \\
\hline
\end{tabular}

$\mathrm{ICU}$, intensive care unit; NIV, noninvasive ventilation; SD, standard deviation

the discretion of the attending intensivist. However, the purpose of our study was to address the issue of prophylactic NIV in a real world scenario. Third, our study is limited by the small sample size with only 10 patients failing extubation at 72 hours. The small sample size limited our ability to explore risk-factors for extubation failure in this subgroup of patients. Finally, we did not explore the role of high flow nasal cannula (HFNC) as a mean to reduce extubation failure or as rescue therapy in patients developing postextubation respiratory failure. Recent studies have shown promising results of HFNC either alone or in combination with NIV compared to NIV alone, in this high-risk patient population. ${ }^{25,26}$

\section{Conclusion}

Despite the limitations of being a single-center study and small sample size, our prospective study could identify higher age, longer duration of invasive ventilation, and higher baseline SOFA score as risk factors for failure of prophylactic NIV in this high-risk patient group. A clear trend toward worsening of SOFA score following failed extubation, re-affirmed the earlier findings of Thille and colleagues and suggests extubation failure as a direct causative factor for clinical deterioration. ${ }^{4}$ The trend toward higher cumulative fluid balance observed in patients with failed extubation, suggest more aggressive de-resuscitation strategy in these high-risk patients.

\section{ACKNOWLedgments}

We sincerely acknowledge the contributions of all staff members and doctors of the Intensive Care Unit, Fortis-Escorts Hospital, Faridabad for their support in conducting the study and in clinical management of the patients. We are thankful to Dr DK Shukla for the statistical analysis of the data. Special thanks to Dr Sonali Ghosh, Consultant Pediatric Intensivist at QRG Health City, Faridabad for her constant encouragement, constructive criticism and critically reviewing the manuscript.

\section{References}

1. Ghosh S, Chawla A, Mishra K, Jhalani R, Salhotra R, Singh A. Cumulative fluid balance and outcome of extubation: a prospective observational study from a general intensive care unit. Indian J Crit Care Med 2018;22(11):767-772. DOI: 10.4103/ijccm.IJCCM_216_18.

2. Epstein SK, Ciubotaru RL, Wong JB. Effect of failed extubation on the outcome of mechanical ventilation. Chest 1997;112(1):186-192. DOI: 10.1378/chest.112.1.186. 
3. Epstein SK, Ciubotaru RL. Independent effects of etiology of failure and time to reintubation on outcome for patients failing extubation. Am J Respir Crit Care Med 1998;158(2):489-493. DOI: 10.1164/ ajrccm.158.2.9711045.

4. Thille AW, Harrois A, Schortgen FD, Brun-Buisson C, Brochard L. Outcomes of extubation failure in medical intensive care unit patients. Crit Care Med 2011;39(12):2612-2618. DOI: 10.1097/ CCM.0b013e3182282a5a.

5. Frutos-Vivar F, Ferguson ND, Esteban A, Epstein SK, Arabi Y, Apezteguía $C$, et al. Risk factors for extubation failure in patients following a successful spontaneous breathing trial. Chest 2006;130(6):1664-1671. DOI: 10.1378/chest.130.6.1664.

6. Ferrer M, Valencia M, Nicolas JM, Bernadich O, Badia JR, Torres A. Early non-invasive ventilation averts extubation failure in patients at risk - a randomized trial. Am J Respir Crit Care Med 2006;173(2):164-170. DOI: $10.1164 / \mathrm{rccm} .200505-7180 C$.

7. Smina M, Salam A, Khamiees M, Gada P, Amoateng-Adjepong $Y$, Manthous CA. Cough peak flows and extubation outcomes. Chest 2003;124(1):262-268. DOI: 10.1378/chest.124.1.262.

8. Salam A, Tilluckdharry L, Amoateng-Adjepong Y, Manthous CA. Neurologic status, cough, secretions and extubation outcomes. Intensive Care Med 2004;30(7):1334-1339. DOI: 10.1007/s00134-0042231-7.

9. Upadya A, Tilluckdharry L, Muralidharan V, Amoateng-Adjepong $Y$, Manthous CA. Fluid balance and weaning outcomes. Intensive Care Med 2005;31(12):1643-1647. DOI: 10.1007/s00134-005-2801-3.

10. Epstein SK, Durbin CG. Should a patient be extubated and placed on non-invasive ventilation after failing a spontaneous breathing trial? Respir Care 2010;55:198-206.

11. Esteban A, Frutos-Vivar F, Ferguson ND, Arabi Y, Apezteguía C, González M, et al. Non-invasive positive-pressure ventilation for respiratory failure after extubation. N Engl J Med 2004;350(24):24522460. DOI: 10.1056/NEJMoa032736.

12. Jiang JS, Kao SJ, Wang SN. Effect of early application of biphasic positive airway pressure on the outcome of extubation in ventilator weaning. Respirology 1999;4(2):161-165. DOI: 10.1046/j.14401843.1999.00168.x.

13. Su CL, Chiang LL, Yang SH, Lin HI, Cheng KC, Huang YCT, et al. Preventive use of non-invasive ventilation after extubation: a prospective, multi-centre randomized controlled trial. Respir Care 2012;57:204-210.

14. Keenan SP, Powers C, McCormack DG, Block G. Non-invasive positivepressure ventilation for post-extubation respiratory distress: a randomized controlled trial. JAMA 2002;287(24):3238-3244. DOI: 10.1001/jama.287.24.3238.

15. Nava S, Gregoretti C, Fanfulla F, Squadrone E, Grassi M, Carlucci A, et al. Non-invasive ventilation to prevent respiratory failure after extubation in high-risk patients. Crit Care Med 2005;33(11):2465-2470. DOI: 10.1097/01.CCM.0000186416.44752.72.

16. Ferrer M, Sellarés J, Valencia M, Carrillo A, Gonzalez G, Badia JR, et al. Non-invasive ventilation after extubation in hypercapnic patients with chronic respiratory disorders: randomised controlled trial. Lancet 2009;374(9695):1082-1088. DOI: 10.1016/S01406736(09)61038-2.

17. Girault C, Bubenheim M, Abroug F, Diehl JL, Elatrous S, Beuret $P$, et al. Non-invasive ventilation and weaning in patients with chronic hypercapnic respiratory failure: a randomized multicentre trial. Am J Respir Crit Care Med 2011;184(6):672-679. DOI: 10.1164/rccm.2011010035OC.

18. Chawla R, Dixit SB, Zirpe KG, Chaudhry D, Khilnani GC, Mehta Y, et al. ISCCM guidelines for the use of Non-invasive ventilation in acute respiratory failure in adult ICUs. Indian J Crit Care Med 2020;24(Suppl 1):S61-S81.

19. Rochwerg B, Brochard L, Elliott MW, Hess D, Hill NS, Nava S, et al. Official ERS/ATS clinical practice guidelines: non-invasive ventilation for acute respiratory failure. Eur Respir J 2017;50(2):1602426. DOI: 10.1183/13993003.02426-2016.

20. Ely EW, Bennett P, Bowton D, Murphy S, Florance A, Haponik E. Large implementation of a respiratory therapist-driven protocol for ventilator weaning. Am J Respir Crit Care Med 1999;159(2):439-446. DOI: 10.1164/ajrccm.159.2.9805120.

21. Boles J-M, Bion J, Connors A, Herridge M, Marsh B, Melot C, et al. Weaning from mechanical ventilation. Eur Respir J 2007;29(5):10331056. DOI: $10.1183 / 09031936.00010206$

22. Levey AS, Eckardt KU, Tsukamoto Y, Levin A, Coresh J, Rossert J, et al. Definition and classification of chronic kidney disease: a position statement from kidney disease: improving global outcomes (KDIGO). Kidney Int 2005;67(6):2089-2100. DOI: 10.1111/j.15231755.2005.00365.x.

23. Fernandez MM, González-Castro A, Magret M, Bouza MT, Ibañez M, García C, et al. Reconnection to mechanical ventilation for $1 \mathrm{~h}$ after a successful spontaneous breathing trial reduces reintubation in critically ill patients: a multi-center randomized controlled trial. Intensive Care Med 2017;43(11):1660-1667. DOI: 10.1007/s00134-0174911-0.

24. Thille AW, Boissier F, Ben-Ghezala H, Razazet K, Mekontso-Dessap A, Brun-Buisson C, et al. Easily identified at-risk patients for extubation failure may benefit from non-invasive ventilation: a prospective before-after study. Crit Care 2016;20(1):48. DOI: 10.1186/s13054-0161228-2.

25. Hernández G, Vaquero C, Colinas L, Cuena R, González P, Canabal $A$, et al. Effect of post-extubation high-flow nasal cannula vs noninvasive ventilation on reintubation and post-extubation respiratory failure in high-risk patients: a randomized clinical trial. JAMA 2016;316(15):1565-1574. DOI: 10.1001/jama.2016. 14194.

26. Thille AW, Muller G, Gacouin A, Coudroy R, Decavèle M, Sonneville R, et al. HIGH-WEAN Study Group and the REVA Research Network Effect of post-extubation high-flow nasal oxygen with noninvasive ventilation vs high-flow nasal oxygen alone on reintubation in patients at high risk of extubation failure. JAMA 2019;322(15):14651475. DOI: 10.1001/jama.2019.14901. 